\title{
Do Adverse Pregnancy Outcomes Predict Under-5 Mortality in Nigeria?
}

\author{
Henry C. Debem \\ Walden University \\ Amany Refaat \\ Walden University \\ Tolulope A. Osoba \\ Walden University
}

Nigerian children under 5 years of age are over 15 times more at risk of death than their counterparts in developed regions of the world; the prevalence of miscarriage, an adverse pregnancy outcome (APO), was estimated at $49 \%$. In the present study, the relationship between APO and under-5 mortality (U5M) in Nigeria was examined to determine if APO could be used as a reliable early warning indicator for U5M. We used a cross-sectional secondary data analysis of datasets from three Nigeria demographic and health surveys: 2003, 2008, and 2013. The study population was women of reproductive age (15-49). Cochran-Mantel-Haenzel chi-square statistics and multiple logistic regression were performed to determine the association, based on maternal socioeconomic factors and access to prenatal healthcare. Results indicated a significant inverse association between APO and U5M. The children of women who have experienced any form of APO may be at lower risk of U5M than children of women who have never had any APO. The implication is that history of APO may not be a reliable early warning indicator for determining higher risk of U5M. These findings suggest further studies to explore the pathway of this association.

Keywords: adverse pregnancy outcomes, women, miscarriage, induced abortion, fetal loss, under-5 mortality, Nigeria

\section{Introduction}

Under-5 mortality (U5M) is a global health concern that has gained considerable attention in many countries. Globally, over 8 million children did not live to see their fifth year in 2008 (Black et al., 2010) and over 6 million in 2013 (World Health Organization [WHO], 2014). The U5M rate informed the fourth goal of the Millennium Development plan, which was to reduce the mortality rate of children under 5 by 67\%, between 1990 and 2015 (United States Agency for International Development [USAID], 2017). However, the global efforts failed on this target, achieving mortality reduction by only a little more than half (90 to 43 deaths per 1,000 live births; United Nations, 2017).

This research is based on the datasets collected in the Nigeria Demographic and Health Survey 2003, 2008, and 2013. The report of this study does not reflect the views and opinions of the University of Liverpool. This manuscript was completed in partial fulfillment of the doctoral requirements in Public Health at the Walden University under the direction of Amany Refaat, PhD. We acknowledge and appreciate the edits made by Timothy Mclndoo to improve the quality of the manuscript.

Please address queries to: Henry C. Debem, who is now at the Faculty of Health Sciences, University of Liverpool. Email: henry.debem@online.liverpool.ac.uk; hcdebem@yahoo.com 
Currently, U5M informs the second target of the third goal of the sustainable development goal, which is to achieve U5M as low as 25 deaths per 1,000 live births by 2030 (United Nations, 2015).

Despite the failure to meet the fourth goal of the millennium development goal, the U5M has shown a universal substantial decline between 1990 and 2013 through the efforts of most developing nations (WHO, 2014). However, the child health situation in Africa, particularly in Nigeria, calls for more strategic intervention. For example, Asia and sub-Saharan Africa alone account for the majority of the global U5M, despite poor records and documentation in the regions (WHO, 2014). At 117 deaths per 1,000 live births in 2013, Nigeria was ranked ninth among the first 10 countries with worst U5M (Central Intelligence Agency, 2014). WHO (2014) noted that children under 5 in subSaharan Africa are 15 times more at risk of U5M than their counterparts in the developed countries in the world; however, studies have not clearly shown whether such risk is associated with residency or nativity in Africa.

WHO (2017) has identified factors that predispose this vulnerable population to premature deaths: poor maternal access to antenatal and quality healthcare deliveries/services, poverty, transportation difficulties, poor immunization, and scarcity of trained personnel in health facilities. In addition, the United States Office of Disease Prevention and Health Promotion (ODPHP, 2014) has reported that maternal health and child health share some common health determinants, such as maternal level of educational attainment, environment, ethnicity, family income, and access to quality healthcare. This implies that the conditions affecting maternal health could affect child health.

ODPHP (2014) reported a pregnancy outcome as a measure of maternal health status. An adverse pregnancy outcome (APO) is defined as any event that did not result in a live birth, for example, miscarriage, induced abortion, and fetal loss (National Population Commission, 2008). Some scholars have also identified several common determinants of U5M and APO. These include socioeconomic conditions of women (such as poor education, low income, and poor environmental setting), age of the mother, occupational stress (such as night duty), and maternal substance abuse, particularly during pregnancy (Ayiko, Antai, \& Kulane, 2009; Bailey \& Sokol, 2011; Ezeh, Agho, Dibley, Hall, \& Page, 2015; Feodor Nilsson, Andersen, Strandberg-Larsen, \& Nybo Andersen, 2014; Kayode, Adekanmbi, \& Uthman, 2012). Other suggested risk factors of U5M include sex of the child (Ayiko et al., 2009; Muoneke, Ibekwe, Nebe-Agumadu, \& Ibe, 2012) and low intervals (less than 24 months) between one childbirth and another (Ayiko et al., 2009; Kayode et al., 2012).

Although no or limited robust population-based work has been reported on the prevalence and incidence of APO in Nigeria, Abiola et al. (2013) suggested that the prevalence of miscarriage is almost 50\% among women of reproductive age who had ever gotten pregnant and received obstetric and gynecological services in a tertiary institution in Nigeria. This finding suggests that approximately 1 in 3.7 pregnancies was lost to miscarriage. It is logical to align the estimated high prevalence of miscarriage with the high U5M rate in Nigeria. However, there is still some obscurity in determining the extent of this association between the history of APO (miscarriage, still birth, and induced abortion), and U5M from the literature. For instance, Kochar, Dandona, Kumar, and Dandona (2014) suggested an inverse association between induced abortion and neonatal mortality in India, and Al-Hosani, Brebner, Bener, and Norman (2003) reported no positive association between history of fetal loss and U5M, despite the common notion that the two outcomes share similar risk factors/determinants.

In addition to common factors of maternal and child health outcomes, access to antenatal and postnatal care services have been noted as significant maternal factors that affect both APO and 
U5M (Joshi, Torvaldsen, Hodgson, \& Hayen, 2014; WHO, 2016). WHO (2016) recommended improved access to quality antenatal healthcare to ensure a healthy gestational process, thus minimizing the risks of APO. Certainly, adequate access to healthcare would not only improve the health of mothers, but would improve children's health by minimizing the risks of neonatal mortality (Joshi et al., 2014; ODPHP, 2014; WHO, 2016). Child immunization has been identified as one of the major innovations of public health in reducing U5M and thus improving children's health (Kitamura, Komada, Xeuatvongsa, \& Hachiya, 2013). Child immunization is the main healthcare service that attracts a majority of mothers to hospitals to participate in postnatal healthcare services (Nankabirwa et al., 2015). Child immunization, just like maternal access to healthcare, has been shown to be a very important factor in studies on child health. For instance, a study on bacille Calmette-Guerin (BCG) vaccines in Uganda noted that BCG vaccination could avert 50\% of BCGrelated child mortality in the country. This suggests that more than half of child deaths related to preventable disease could be attributed to poor child vaccination.

However, the possible association between APO and U5M is not yet clear in the literature, as there have not been adequate exploration of these outcomes beyond their risk factors. In the present study, we investigated the relationship between APO and U5M as an exploration of the relationship between maternal and child health factors using the theoretical framework of fetal programming (FP) and life course health development (LCHD; Lynch, 2008; Nicoletto \& Rinaldi, 2011). This study would further contribute to knowledge and provide more clarity on the possible relationship between the outcomes. The practical implication of the study is an exploration of potential early warning indicators of U5M from maternal historical events, such as a previous APO. History and/or experience of an APO could be an important early indicator of women who may be at risk of losing their children within the first 5 years of life. Hence, informing the focus of early U5M preventive support. A study implication could also be a potential life course approach to control U5M in Nigeria and other African countries.

The LCHD theory originated between 1920 and 1930, by Thomas and Znaniecki (Elder, 1998). It was conceived from the longitudinal studies conducted by the authors to investigate child development processes and circumstances leading to adulthood. However, the theory was not popular among scholars until the 1960s when it reached its first public awareness (Elder, 1998; Elder, Johnson, \& Crosnoe, 2003). The theory postulates that one's future health outcomes are due to complex interplay among one's historical social, behavioral, and environmental factors rather than immediate biomedical causes and that the historical circumstances could be traced to previous generations that account for one's maternal factors (Elder et al., 2003; Halfon, Larson, Lu, Tullis, \& Russ, 2014). Similarly, FP was propounded by Barker, a clinical epidemiologist, in the early 1990s. Barker provided in-depth insight on the leading role of certain biopsychosocial circumstances during pregnancy in determining the health outcomes of the offspring after delivery and beyond (Barker, 2007; Collins, Rankin, \& David, 2011). Collins et al. demonstrated this in a study in which mothers born at low birth weight showed a consistent adverse birth pattern in their own deliveries.

Therefore, the LCHD and FP theories attempt to link the events of one's past, both in the earlier generation and/or antenatal era, with one's prevailing health developments and outcomes. As the LCHD suggests that the earlier social circumstances or habitual factors of a woman in her generation could influence her health outcomes in the future or that of her children in the next generation (Lynch, 2008); the FP suggests a similar impact of prenatal or fetal development events on the children's future outcomes (Nicoletto \& Rinaldi, 2011). The principles of the LCHD and FP theories align with the contextual assumptions of the study better than other life developmental theories. The theories imply that healthy pregnancy or pregnancy outcomes, as a function of 
maternal health, could be subject to the earlier and prevailing determinants of health experienced by a woman and that a child's health, indicated by under age 5 morbidity and mortality, could be connected to the maternal health circumstances and outcomes. The purpose of this study was to investigate the relationship between the history of APO and U5M, as well as to explore the potential use of APO as an early warning indicator for U5M.

\section{Method}

\section{Study Aim/Context}

The present study examined the association between the history of APO among women of reproductive age (15-49) and the death of their children under age 5 across three consecutive survey years—2003, 2008, and 2013.

Research Question: What is the extent of the relationship between the history of APO and the U5M, given the maternal-socioeconomic conditions, age of the woman, sex of the child, and maternal access to prenatal healthcare?

\section{Study Population}

The study population was women of reproductive age (15-49). The exclusion criterion was no live birth within the 5 years preceding the survey years. The respective samples of women interviewed in the original (primary) surveys across the years of interest were $38,948,33,385$, and 7,620 in 2013 , 2008 , and 2003, respectively. However, the valid sample sizes after conducting the selection criteria were $20,467,17,635$, and 3,911 in 2013, 2008, and 2003 respectively. The idea of pooling data from three consecutive surveys was to generate a sufficient sample size after the exclusions, including missing data (participants with incomplete relevant information), and to examine consistencies across time for any possible time-related differences of interest.

\section{Study Design}

The study was a secondary data analysis of the datasets from the Nigerian Demographic and Health Survey (NDHS), a periodic population and household based cross-sectional survey that elicits information from every member of the selected households through multistage cluster sampling (USAID, 2015b). The survey collected information through face-to-face interviews using three types of questionnaires designed to elicit relevant information from women, men, and households (USAID, 2015b). The surveys used a three-stage, cluster-stratified sampling strategy, designed to generate samples that were nationally representatives of the country's population. Detailed procedures for the sampling were described in the NDHS reports (National Population Commission, 2013). Key information of interest about the children under 5 who were born within the last 5 years preceding the surveys and other relevant past life events—-such as past APO—were elicited retrospectively from the women.

\section{Variables of Interest and Descriptions}

The outcome variable was U5M, which was described as the death of a child under the age of 5 years within the 5 years preceding the survey period. However, we were aware of the possibilities of multiple births and pregnancies within the 5-year period, as well as recall errors on the exact birth dates and types of some births, particularly among the uneducated and rural residents. To improve the quality of the records for this analysis, we restrained our records on information about the last 
live birth (from single or multiple births) within the last 5 years, which was more likely to be accurate. The exposure variable was history of APO, which is described as the occurrence of any APO, such as miscarriage, fetal loss, or induced abortion (according to NDHS), that did not result in a live birth in the past, that is, before the 5 -year period preceding the survey years. For example, for the 2008 survey, the history of APO referred to an occurrence of any known APO event not later than 2003.

From the literature, we were able to identify some important covariates as potential confounders and/or effect modifiers, such as age of the mother, sex of the child, maternal socioeconomic factors (education levels, wealth status, occupational status, residential setting), and access to prenatal healthcare. The age of the mother was the current age of the participant at the time of the surveys, the sex of the child was the sex of the child at the time of the surveys (if alive) or before the child's death (if dead), and the education level was the highest educational level attained by the participant. The wealth status was the wealth index of the participants as computed and categorized by the NDHS, and the occupational status was the current work status of the participant at the time or within 12 months preceding the surveys. The residential setting was the type of the developmental setting (rural/urban) in which the participant lived at the time of the survey, and access to prenatal healthcare determined whether the participant received any form of prenatal/antenatal healthcare services for the last child of interest.

\section{Procedures and Data Collection}

The datasets used in this study were accessible online from the Demographic Health Survey (DHS) carried out by the USAID protected public domain (USAID, 2015a). Authorized access was required, meaning that the host requires due registration and a letter of permission to intended data users/authors, following the stipulated access guidance (USAID, 2015a). The women's datasets were downloaded and further codified and transformed to suit the purpose of the study.

\section{Statistical Tests/Data Analysis Plan}

SPSS Version 20.1 was used to perform the analyses. All analyses were set and interpreted at a $95 \%$ confidence interval and 5\% alpha level. All analyses were weighted following the DHS guidance on weighting DHS data (USAID, 2016). Descriptive statistics described the demographic characteristics of the sampled population. All relevant categorical demographic variables across the relevant datasets were presented in frequency tables and charts to demonstrate important demographic patterns across the survey years.

The Cochran-Mantel-Haenszel chi-squared statistics were performed to determine the association between the study variables, under the null hypothesis of conditional independence equal to odds ratio $(O R)=1$, given the various covariates identified. Multiple logistic regression was used to determine the strength of the association, given the interactive effects of multiple covariates in the model (Field, 2013)

\section{Ethical Approval}

As a secondary analysis, the present study did not involve any direct interactions with human and animal subjects; however, it was reviewed and approved by the Walden University Institutional Review Board (Approval Number: 03-25-16-0331537). 


\section{Results}

\section{Demographic Characteristics}

Table 1 demonstrates that the age distributions of the participants across the 3 survey years were similar. The mean and median ages of the participants were the same (29 years) across the years, with standard deviations of approximately 7.0, strengthening the evidence that the age distributions of the samples were very similar and comparable. The weighted sample sizes in 2003, 2008, and 2013 were $3,911,17,635$, and 20,467, respectively. More than a quarter $(26 \%-27 \%)$ of the women were young adults between the ages of 25 and 29 years. Many $(46 \%-51 \%)$ had no formal education. The majority (64\%-69\%) of the women had some form of job to earn a living; however, nearly half $(44 \%-45 \%)$ had poor earnings. A high proportion $(64 \%-71 \%)$ of the women lived in rural areas. Although information on the ethnic distribution of the participants was not available in the 2003 sample, the information on the other samples demonstrated that they were dominated by the Hausa tribe (29\%-34\%), followed by Yoruba (12\%-15\%) and Igbo (11\%-12\%) tribes. Almost all the women $(91 \%-93 \%)$ were married. The prevalence of U5M was $6.6 \%$, demonstrating a decreasing trend from 2003 (8.8\%) to 2013 (5.8\%). However, almost half (48.2\%) of the women had experienced an APO at some point in their lives before the 5-year period preceding the survey years. There was no consistent pattern of APO across the years (47.1\%, 49.5\%, and 47.1\% in 2003, 2008, and 2013, respectively).

Table 1. Key Demographic Descriptions of the Samples: Frequencies and Percentages

\begin{tabular}{|c|c|c|c|c|c|c|}
\hline \multirow{2}{*}{$\begin{array}{l}\text { Demographic } \\
\text { Characteristics }\end{array}$} & \multicolumn{2}{|c|}{$2003^{a}$} & \multicolumn{2}{|c|}{$2008^{b}$} & \multicolumn{2}{|c|}{$2013^{c}$} \\
\hline & $n$ & $\%$ & $n$ & $\%$ & $n$ & $\%$ \\
\hline \multicolumn{7}{|l|}{ Age groups } \\
\hline $15-19$ & 356 & 9.1 & 1,168 & 6.6 & 1,323 & 6.5 \\
\hline $20-24$ & 850 & 21.7 & 3,399 & 19.3 & 4,009 & 19.6 \\
\hline $25-29$ & 1,055 & 27.0 & 4,694 & 26.6 & 5,376 & 26.3 \\
\hline $30-34$ & 713 & 18.2 & 3,617 & 20.5 & 4,247 & 20.7 \\
\hline $35-39$ & 541 & 13.8 & 2,671 & 15.1 & 3,172 & 15.5 \\
\hline $40-44$ & 308 & 7.9 & 1,416 & 8.0 & 1,656 & 8.1 \\
\hline $45-49$ & 88 & 2.2 & 671 & 3.8 & 684 & 3.3 \\
\hline Total $(n)$ & 3,911 & 100.0 & 17,635 & 100 & 20,467 & 100.0 \\
\hline \multicolumn{7}{|c|}{ Highest education level } \\
\hline No education & 1,989 & 50.8 & 8,017 & 45.5 & 9,794 & 47.9 \\
\hline Primary & 918 & 23.5 & 4,012 & 22.8 & 3,915 & 19.1 \\
\hline Secondary & 861 & 22.0 & 4,557 & 25.8 & 5,475 & 26.7 \\
\hline Higher & 142 & 3.7 & 1,050 & 6.0 & 1,283 & 6.3 \\
\hline Total $(n)$ & 3,911 & 100.0 & 17,635 & 100.0 & 20,467 & 100.0 \\
\hline \multicolumn{7}{|c|}{ Occupational status } \\
\hline No & 1,421 & 36.4 & 5,967 & 34.1 & 6,365 & 31.2 \\
\hline Yes & 2,481 & 63.6 & 11,544 & 65.9 & 14,008 & 68.8 \\
\hline Total $(n)$ & 3,902 & 100.0 & 17,511 & 100.0 & 20,373 & 100.0 \\
\hline
\end{tabular}




\begin{tabular}{|c|c|c|c|c|c|c|}
\hline \multirow{2}{*}{$\begin{array}{l}\text { Demographic } \\
\text { Characteristics }\end{array}$} & \multicolumn{2}{|c|}{$2003^{a}$} & \multicolumn{2}{|c|}{$2008^{b}$} & \multicolumn{2}{|c|}{$2013^{c}$} \\
\hline & $n$ & $\%$ & $n$ & $\%$ & $n$ & $\%$ \\
\hline \multicolumn{7}{|l|}{ Wealth index } \\
\hline Poorest & 852 & 21.8 & 4,074 & 23.1 & 4,699 & 23.0 \\
\hline Poorer & 846 & $21.6 \mathrm{~s}$ & 3,916 & 22.2 & 4,588 & 22.4 \\
\hline Middle & 808 & 20.7 & 3,350 & 19.0 & 3,902 & 19.1 \\
\hline Richer & 735 & 18.8 & 3,204 & 18.2 & 3,674 & 18.0 \\
\hline Richest & 670 & 17.1 & 3,091 & 17.5 & 3,604 & 17.6 \\
\hline Total $(n)$ & 3,911 & 100.0 & 17,635 & 100.0 & 20,467 & 100.0 \\
\hline \multicolumn{7}{|l|}{ Type of residence } \\
\hline Urban & 1,144 & 29.3 & 5,330 & 30.2 & 7,278 & 35.6 \\
\hline Rural & 2,767 & 70.7 & 12,305 & 69.8 & 13,189 & 64.4 \\
\hline Total $(n)$ & 3,911 & 100.0 & 17,635 & 100.0 & 20,467 & 100.0 \\
\hline \multicolumn{7}{|l|}{ Ethnicity } \\
\hline Hausa & - & - & 5,113 & 29.0 & 6,991 & 34.2 \\
\hline Igbo & - & - & 2,039 & 11.6 & 2,213 & 10.8 \\
\hline Yoruba & - & - & 2,638 & 15.0 & 2,487 & 12.2 \\
\hline Others & - & - & 7,845 & 44.5 & 8,776 & 42.9 \\
\hline Total $(n)$ & - & - & 17,635 & 100.0 & 20,467 & 100.0 \\
\hline \multicolumn{7}{|l|}{ Marital status } \\
\hline Never married & 117 & 3.0 & 422 & 2.4 & 452 & 2.2 \\
\hline $\begin{array}{l}\text { Married (living } \\
\text { together) }\end{array}$ & 3,546 & 90.7 & 16,355 & 92.7 & 18,860 & 92.1 \\
\hline $\begin{array}{l}\text { Living together (not } \\
\text { married) }\end{array}$ & 104 & 2.6 & 321 & 1.8 & 537 & 2.6 \\
\hline Widowed & 34 & 0.9 & 227 & 1.3 & 252 & 1.2 \\
\hline Divorced & 66 & 1.7 & 136 & 0.8 & 201 & 1.0 \\
\hline $\begin{array}{l}\text { Not living together } \\
\text { (married) }\end{array}$ & 43 & 1.1 & 173 & 1.0 & 165 & 0.8 \\
\hline Total $(n)$ & 3,911 & 100.0 & 17,634 & 100.0 & 20,467 & 100.0 \\
\hline
\end{tabular}

\section{Cross-Tabulation of History of APO and U5M Across the Survey Years}

Table 2 shows a consistent inverse pattern in the association between APO and U5M. Across the years $(2003,2008$, and 2013), more women $(16.3 \%, 11.1 \%$, and $10.8 \%$, respectively) among those who did not have any record of APO tended to have lost more children under age 5 than those who had experienced APO (7.5\%, 6.9\%, and 6.7\%, respectively). 
Table 2. Cross-Tabulation of History of Adverse Pregnancy Outcome (APO) and Under-5

Mortality Across the 3 Survey Years

\begin{tabular}{|c|c|c|c|}
\hline \multirow[b]{2}{*}{ History of APO } & \multicolumn{3}{|c|}{ Under-5 Mortality } \\
\hline & No & Yes & Total \\
\hline \multicolumn{4}{|l|}{2003 Survey } \\
\hline \multicolumn{4}{|l|}{ No } \\
\hline$n$ & 287 & 56 & 343 \\
\hline$\%$ & $83.7 \%$ & $16.3 \%$ & $100 \%$ \\
\hline \multicolumn{4}{|l|}{ Yes } \\
\hline$n$ & 283 & 23 & 306 \\
\hline$\%$ & $92.5 \%$ & $7.5 \%$ & $100 \%$ \\
\hline \multicolumn{4}{|l|}{ Total } \\
\hline$n$ & 570 & 79 & 649 \\
\hline$\%$ & $87.8 \%$ & $12.2 \%$ & $100 \%$ \\
\hline \multicolumn{4}{|l|}{2008} \\
\hline \multicolumn{4}{|l|}{ No } \\
\hline$n$ & 1,012 & 126 & 1,138 \\
\hline$\%$ & $88.9 \%$ & $11.1 \%$ & $100 \%$ \\
\hline \multicolumn{4}{|l|}{ Yes } \\
\hline$n$ & 1,041 & 77 & 1,118 \\
\hline$\%$ & $93.1 \%$ & $6.9 \%$ & $100 \%$ \\
\hline \multicolumn{4}{|l|}{ Total } \\
\hline$n$ & 2,053 & 203 & 2,256 \\
\hline$\%$ & $91.0 \%$ & $9.0 \%$ & $100 \%$ \\
\hline \multicolumn{4}{|l|}{2013} \\
\hline \multicolumn{4}{|l|}{ No } \\
\hline$n$ & 1,118 & 136 & 1,254 \\
\hline$\%$ & $89.2 \%$ & $10.8 \%$ & $100 \%$ \\
\hline \multicolumn{4}{|l|}{ Yes } \\
\hline$n$ & 1,042 & 75 & 1,117 \\
\hline$\%$ & $93.3 \%$ & $6.7 \%$ & $100 \%$ \\
\hline \multicolumn{4}{|l|}{ Total } \\
\hline$n$ & 2,160 & 211 & 2,371 \\
\hline$\%$ & $91.1 \%$ & $8.9 \%$ & $100 \%$ \\
\hline
\end{tabular}

\section{Test of Association Using Cochran-Mantel-Haenzel Statistics}

The results in Table 3 demonstrated strong evidence that the observed inverse association between history of APO and U5M was statistically significant at $O R=0.56,95 \%$ confidence interval [CI] $[0.46,0.68]$. This shows that the risk of U5M was $44 \%$ lower among children of women who had experienced APO than those who had not recorded any APO event in their lives. Further control for the potential confounders and/or effect modifiers retained the strong evidence of association across the covariates, such as maternal educational level, $O R=0.53,95 \%$ CI [0.44, 0.65]; maternal age, $O R$ $=0.50,95 \%$ CI $[0.41,0.61]$; residential settings, $O R=0.56,95 \%$ CI $[0.46,0.68]$; sex of the child, $O R=$ $0.55,95 \%$ CI [0.46, 0.68]; occupational status, $O R=0.56,95 \%$ CI [0.46, 0.68]; wealth index, $O R=$ $0.54,95 \%$ CI $[0.44,0.65]$; and access to prenatal healthcare $O R=0.54,95 \%$ CI $[0.44,0.66]$. This finding shows that the covariates had no significant influence on the association. The result of the multiple logistic regression showed strong evidence of a statistically significant, inverse association between history of APO and U5M at $O R=0.47,95 \%$ CI $[0.38,0.57]$. The results of the regression 
model suggested strong evidence that the risk of losing a child under age 5 among women who had experienced APO was lower (by 53\%) than those who had no experience of APO.

Table 3. Logistic Model and Cochran-Mantel-Haenzel (CMH) Test of Association Between History of Adverse Pregnancy Outcome (APO) and Under-5 Mortality, Adjusting for Other Covariates

\begin{tabular}{|c|c|c|c|c|c|c|}
\hline \multirow[b]{3}{*}{ CMH } & \multirow{3}{*}{$\begin{array}{c}\text { Mantel- } \\
\text { Heanzel } \chi^{2}\end{array}$} & \multirow[b]{3}{*}{$d f$} & \multicolumn{4}{|c|}{ Odds Ratio } \\
\hline & & & \multirow{2}{*}{$\begin{array}{c}\text { Sig. of } \\
\text { Homogeneity }\end{array}$} & \multirow[b]{2}{*}{ M-H } & \multicolumn{2}{|c|}{$95 \%$ CI } \\
\hline & & & & & Lower & Upper \\
\hline Survey years & $34.2^{\mathrm{a}^{* * *}}$ & 1 & 0.46 & 0.56 & 0.46 & 0.68 \\
\hline Level of education & $40.3^{\mathrm{b}^{* * *}}$ & 1 & 0.80 & 0.53 & 0.44 & 0.65 \\
\hline Age group & $46.5^{\mathrm{b}^{* \star *}}$ & 1 & 0.35 & 0.50 & 0.41 & 0.61 \\
\hline Residential setting & $35.2^{\mathrm{b}^{* * *}}$ & 1 & 0.38 & 0.56 & 0.46 & 0.68 \\
\hline Sex of child & $35.9^{\mathrm{b}^{* * *}}$ & 1 & 0.67 & 0.55 & 0.46 & 0.67 \\
\hline Occupational status & $34.3^{\mathrm{b}^{* * *}}$ & 1 & 0.68 & 0.56 & 0.46 & 0.68 \\
\hline Wealth index & $39.0^{\mathrm{b}^{* * *}}$ & 1 & 0.81 & 0.54 & 0.44 & 0.65 \\
\hline Prenatal healthcare & $36.9 \mathrm{~b}^{* * *}$ & 1 & 0.43 & 0.54 & 0.44 & 0.66 \\
\hline Logit model & Wald & & $\begin{array}{c}\text { Negelkerke } \\
R^{2} \\
\end{array}$ & $\operatorname{Exp}(B)$ & & \\
\hline History of APO & $53.0^{\mathrm{c}^{* * *}}$ & 1 & $6.3 \%$ & 0.47 & 0.38 & 0.57 \\
\hline
\end{tabular}

\section{Discussion}

The demographic characteristics of the study population were similar and comparable across the 3 survey years. The samples were dominated by poorly educated, married, young adults living in the rural areas with poor economic status. These characteristics were obtainable in all the individual study years, suggesting the status of a common reproductive-age woman in Nigeria. This also suggests the homogeneity of the study population across the survey years; however, there were slight regular patterns observed among the demographic variables from 2003 to 2013 that may influence the association between history of APO and U5M. For example, the results demonstrated patterns of improvement in various educational levels, in occupational status, and in rural to urban migration. Nonetheless, the poverty status measured by wealth index worsened over the period.

The study demonstrated a likely improvement pattern in the prevalence of U5M among last-born children between 2003 (8.8\%) and 2013 (5.8\%). However, the prevalence of APO within the same survey period did not seem to follow any meaningful pattern; thus, it remained the same with the all-time (historical) mean prevalence of $48.2 \%$, which suggests that almost half of the women in Nigeria who conceived could experience one type of APO or the other some point in their lives. This is in agreement with the report from Abiola et al (2013), which suggests that about $49 \%$ prevalence of miscarriage cases among the women who have had conceived in Nigeria. The improvement pattern on U5M shows that the proportion of women whose children die within their first 5 years may be gradually reducing, thus suggesting gradual reduction in the U5M rate and prevalence in the 
country. This finding tends to agree with report by the World Bank (2015), which showed that Nigeria demonstrated a slight improvement in the U5M rate between 2010 and 2013. This supports the idea that the U5M prevalence measurement in similar studies could serve as a good proxy for determining the trend of U5M rate. However, caution should be applied in interpreting the results considering the study population used in determining the prevalence. The results have also shown that the women's attitudes to accessing healthcare during pregnancy (as among the risk factors of maternal and child health) might have improved over time.

This study determined whether the children of women who had any APO experience in the past were more or less likely to die before the age of 5 years. The hypothesis that APO could be associated with U5M stemmed from the fact that these two outcomes share similar factors and circumstances. For example, Ezeh et al. (2015), Ayiko et al. (2009), and ODPHP (2014) reported that the socioeconomic status of a woman or household was associated with U5M. In another study, Kochar et al. (2014) noted the significant impact of socioeconomic status on APO among women of reproductive age in India. Similar findings were made of maternal illicit substance abuse with APO (Feodor Nilsson et al., 2014) and neonatal death (Bailey \& Sokol, 2011; Greenwood et al., 2010). Thus, it is logical to hypothesize that these two health outcomes could be associated in direct positive proportion and could have useful practical implications due to the temporality that exists among the outcomes, that is, APO occurring before U5M by chronological process. However, the study clearly demonstrated an inverse statistically significant association between the history of APO and U5M after controlling for all other potential confounders and effect modifiers.

Though the result showed an expected significant effect based on the literature, the direction of the association was unexpected. An inverse association from the study was an indication that the occurrence of APO may have conferred additional immunity against the risks of U5M to the children of the women who had experienced the adverse events compared to those who had not experienced any adverse events. This finding tended to agree with the report of Kochar et al. (2014) and AlHosani et al (2003). While the former determined an adverse association between induced abortion (a type of APO) and neonatal mortality (a subset of U5M), the latter suggested no positive associations between the history of fetal loss and U5M. Although subject to more robust studies, the present findings suggest that women who had experienced any form of APO may have been spurred by such experience to provide more healthy measures in caring for their children and thus, ameliorate the risk of U5M. Such precautions may include regular uptake of early and adequate immunization services for the child, and strict compliance with other medical and health instructions.

The pathway for this association was not clear from the literature. However, one could hypothesize a psychobehavioral pathway as the main process underlying this association. The psychological effect of losing a previous pregnancy could stimulate conscientious attitudes toward, or habits of, caring for future live births. Such habits could minimize child morbidity and mortality cases. However, information on child immunization status of the children could not be ascertained from the NDHS dataset because there was no immunization information for the children who died under age 5 . All the same, other relevant covariates, such as maternal access to prenatal healthcare services and maternal socioeconomic factors that have strong associations with U5M (Joshi et al., 2014; WHO, 2016), demonstrated no influence on this relationship. This association is open for further exploration through the LCHD, FP, and/or behavioral contextual theories to identify the possible pathways of the associations. 
To improve interpretations of the findings, certain study limitations should be considered. The U5M and APO measurements were estimated from the reported experience of the women and not from a direct count from reliable records; thus, the reports may lack some accuracy due to information bias and recall errors. It should also be noted that most women were not experienced in detecting or recognizing minor and mild miscarriages, except for those detected clinically and made known to them (Abiola et al., 2013). Thus, a good measure of this outcome could be lost and the true prevalence of the outcome in the populations could be underreported in the surveys. The determination of U5M prevalence was among the respondents' reported last live births within the 5year period of interest preceding the surveys. This was to improve the quality of information on the date and age of birth of the children. Hence, there were other live births within the period whose information was not used because they were not among the last births from the respondents. Thus, the U5M prevalence reported in the study might not be accurate estimates of the under-5 population.

As is typical with the cross-sectional designs and methods, the identified associations among the variables do not imply causality. Because much of the theoretical context of the study was based on the LCHD and FP theories and the study considered the temporality of the study events (the study reviewing the APO events that occurred preceding the 5-year period in which the live births occurred), causality was not implied. However, the findings concurred with the fundamental ideologies of the theories, which demonstrated a possible association between the maternal and child health outcomes. The direction and physiological pathway of the association in the context of the theories is not clear, thus, may require further robust examinations.

The livelihood of the any society seems subject to the protection of the fundamental human rights of women because women are the seeds of creation and sources of nurture for the children (Demos \& Segal, 1999). However, this knowledge is not reflected in most societies in the world, despite the current global campaign for gender equality, particularly on essential socioeconomic rights (Edwards, 2015). A significant proportion of women in the developing countries still suffer several debilitating adverse conditions, such as domestic violence (Asling-Monemi, Tabassum Naved, \& Persson, 2008), poor education, and low-income professions (Cundiff, Uchino, Smith, \& Birmingham, 2015). These socioeconomic conditions have been shown to predispose these women and their children to adverse health outcomes (Mativo, Onyango, \& Ombaka, 2015). Thus, the study is poised to contribute to knowledge and policies that could protect women in society. It could incite further researches and voices in support of global drive for the promotion of maternal and child health through gender balancing and attention to women's fundamental rights in Nigeria.

\section{Conclusions}

The study demonstrated that the association between the history of APO and U5M was inversely and statistically significant. Thus, the children of women who have experienced any form of APO may be at lower risk of death within their first 5 years of life than the children of women who never experienced an APO. The study was able to demonstrate consistency or reliability of the association across the 3 years of the survey. Thus, the history of APO as a maternal factor may be able to confer some level of improved quality of health to the child. The practical implication is that history of APO may not be a reliable early warning indicator for determining women whose children may be at higher risk of U5M. Nevertheless, this study could provoke future robust studies to explore the pathway of the association between these maternal and child health factors and identify the applicable theoretical context that could be applied to future public health interventions on maternal and child health and thus reducing U5M in Nigeria. 


\section{References}

Abiola, A. O., Ajayi, A., Umeh, C. S., Adegbesan-Omilabu, M. O., Olufunlayo, T. F., \& Akodu, B. A. (2013). Knowledge, prevalence and psychological effect of miscarriage among women of reproductive age group attending obstetrics and gynaecology clinics of Lagos University Teaching Hospital, Nigeria. The Nigerian Postgraduate Medical Journal, 20, 319-324.

Al-Hosani, H. A., Brebner, J., Bener, A. B., \& Norman, J. N. (2003). Study of mortality risk factors for children under age 5 in Abu Dhabi. Eastern Mediterranean Health Journal, 9, 333-343.

Asling-Monemi, K., Tabassum Naved, R., \& Persson, L. A. (2008). Violence against women and the risk of under-five mortality: Analysis of community-based data from rural Bangladesh. Acta Paediatrica, 97, 226-232. doi:10.1111/j.1651-2227.2007.00597.x

Ayiko, R., Antai, D., \& Kulane, A. (2009). Trends and determinants of under-five mortality in Uganda. East African Journal of Public Health, 6, 136-140.

Bailey, B. A., \& Sokol, R. J. (2011). Prenatal alcohol exposure and miscarriage, stillbirth, preterm delivery, and sudden infant death syndrome. Alcohol Research \& Health, 34, 86-91.

Barker, D. J. P. (2007). The origins of the developmental origins theory. Journal of Internal Medicine, 261, 412-417. doi:10.1111/j.1365-2796.2007.01809.x

Black, R. E., Cousens, S., Johnson, H. L., Lawn, J. E., Rudan, I., Bassani, D. G., ... Child Health Epidemiology Reference Group of WHO and UNICEF. (2010). Global, regional, and national causes of child mortality in 2008: A systematic analysis. Lancet, 375, 1969-1987. doi:10.1016/S0140-6736(10)60549-1

Central Intelligence Agency. (2014). The world factbook: Life expectancy at birth. Retrieved March 7, 2017, from https://www.cia.gov/library/publications/the-worldfactbook/rankorder/2102rank.html

Collins, J. W., Rankin, K. M., \& David, R. J. (2011). African American women's lifetime upward economic mobility and preterm birth: the effect of fetal programming. American Journal of Public Health, 101, 714-719. doi:10.2105/AJPH.2010.195024

Cundiff, J. M., Uchino, B. N., Smith, T. W., \& Birmingham, W. (2015). Socioeconomic status and health: Education and income are independent and joint predictors of ambulatory blood pressure. Journal of Behavioral Medicine, 38, 9-16. doi:10.1007/s10865-013-9515-8

Demos, V. P., \& Segal, M. T. (Eds.). (1999). Advances in gender research, Vol. 4: Social change for women and children. Bingley, United Kingdom: Emerald Group.

Elder, G. H. (1998). The life course as developmental theory. Child Development, 69, 1-12.

Elder, G. H., Johnson, M. K., \& Crosnoe, R. (2003). The emergence and development of life course theory. In J. T. Mortimer \& M. J. Shanahan, M. J. (Eds.), Handbook of the life course (pp. 319). Boston, MA: Springer. doi:10.1007/978-0-306-48247-2_1

Ezeh, O. K., Agho, K. E., Dibley, M. J., Hall, J. J., \& Page, A. N. (2015). Risk factors for postneonatal, infant, child and under-5 mortality in Nigeria: a pooled cross-sectional analysis. BMJ Open, 5, e006779. doi:10.1136/bmjopen-2014-006779

Feodor Nilsson, S., Andersen, P. K., Strandberg-Larsen, K., \& Nybo Andersen, A.-M. (2014). Risk factors for miscarriage from a prevention perspective: A nationwide follow-up study. BJOG: An International Journal of Obstetrics and Gynaecology, 121, 1375-1384. doi:10.1111/14710528.12694 
Field, A. (2013). Discovering statistics using IBM SPSS statistics (4th ed.). Thousand Oaks, CA: Sage.

Greenwood, D. C., Alwan, N., Boylan, S., Cade, J. E., Charvill, J., Chipps, K. C., ... Wild, C. P. (2010). Caffeine intake during pregnancy, late miscarriage and stillbirth. European Journal of Epidemiology, 25, 275-280. doi:10.1007/s10654-010-9443-7

Halfon, N., Larson, K., Lu, M., Tullis, E., \& Russ, S. (2014). Lifecourse health development: Past, present and future. Maternal and Child Health Journal, 18, 344-365. doi:10.1007/s10995013-1346-2

Joshi, C., Torvaldsen, S., Hodgson, R., \& Hayen, A. (2014). Factors associated with the use and quality of antenatal care in Nepal: A population-based study using the demographic and health survey data. BMC Pregnancy and Childbirth, 14, 94. doi:10.1186/1471-2393-14-94

Kayode, G. A., Adekanmbi, V. T., \& Uthman, O. A. (2012). Risk factors and a predictive model for under-five mortality in Nigeria: Evidence from Nigeria demographic and health survey. $B M C$ Pregnancy and Childbirth, 12, 10. doi:10.1186/1471-2393-12-10

Kitamura, T., Komada, K., Xeuatvongsa, A., \& Hachiya, M. (2013). Factors affecting childhood immunization in Lao People's Democratic Republic: A cross-sectional study from nationwide, population-based, multistage cluster sampling. Bioscience Trends, 7, 178-185.

Kochar, P. S., Dandona, R., Kumar, G. A., \& Dandona, L. (2014). Population-based estimates of still birth, induced abortion and miscarriage in the Indian state of Bihar. BMC Pregnancy and Childbirth, 14, 413. doi:10.1186/s12884-014-0413-z

Lynch, S. M. (2008). Race, socioeconomic status, and health in life-course perspective: Introduction to the special issue. Research on Aging, 30, 127-136. doi:10.1177/0164027507312086

Mativo, N., Onyango, R., \& Ombaka, J. (2015). Socio-demographic factors influencing maternal and child health service utilization in Mwingi: A rural semi-arid district in Kenya. American Journal of Public Health Research, 3, 21-30.

Muoneke, V. U., Ibekwe, R. C., Nebe-Agumadu, H. U., \& Ibe, B. C. (2012). Factors associated with mortality in under-five children with severe anemia in Ebonyi, Nigeria. Indian Pediatrics, 49, 119-123.

Nankabirwa, V., Tumwine, J. K., Mugaba, P. M., Tylleskär, T., Sommerfelt, H., \& PROMISE-EBF Study Group. (2015). Child survival and BCG vaccination: A community based prospective cohort study in Uganda. BMC Public Health, 15, 175. doi:10.1186/s12889-015-1497-8

National Population Commission. (2008). Nigeria demographic and health survey 2008 [FR222]. Retrieved from http://www.dhsprogram.com/pubs/pdf/FR222/FR222.pdf

National Population Commission. (2013). Nigeria demographic and health survey 2013 [FR293]. Retrieved from https://dhsprogram.com/pubs/pdf/FR293/FR293.pdf

Nicoletto, S. F., \& Rinaldi, A. (2011). In the womb's shadow: The theory of prenatal programming as the fetal origin of various adult diseases is increasingly supported by a wealth of evidence. EMBO Reports, 12, 30-34. doi:10.1038/embor.2010.199

Office of Disease Prevention and Health Promotion (ODPHP). (2014). Maternal, infant, and child health: Healthy People 2020. Retrieved from https://www.healthypeople.gov/2020/topicsobjectives/topic/maternal-infant-and-child-health

The World Bank. (2015). Mortality rate, under-5 (per 1,000 live births): Data. Retrieved from http://data.worldbank.org/indicator/SH.DYN.MORT 
United Nations. (2015). Transforming our world: The 2030 agenda for sustainable development: Sustainable development knowledge platform. Retrieved from https://sustainabledevelopment.un.org/post2015/transformingourworld

United Nations. (2017). United Nations millennium development goals. Retrieved from http://www.un.org/millenniumgoals/childhealth.shtml

United States Agency for International Development (USAID). (2015a). The DHS Program: Accessing and using DHS datasets for analysis. Retrieved from http://www.dhsprogram.com/data/Using-DataSets-for-Analysis.cfm

United States Agency for International Development (USAID). (2015b). The DHS Program: Demographic and Health Survey (DHS): What we do. Retrieved from http://dhsprogram.com/What-We-Do/Survey-Types/DHS.cfm

United States Agency for International Development (USAID). (2016). Sampling and weighting with DHS Data: The DHS Program blog. Retrieved from http://blog.dhsprogram.com/samplingweighting-at-dhs/

United States Agency for International Development (USAID). (2017). Infant and child development: Volume 19, Issue 1: Towards a fetal psychology. Retrieved from http://onlinelibrary.wiley.com/doi/10.1002/icd.v19:1/issuetoc

World Health Organization (WHO). (2014). Children: Reducing mortality. Retrieved from http://www.who.int/mediacentre/factsheets/fs178/en/

World Health Organization (WHO). (2016). WHO recommendations on antenatal care for a positive pregnancy experience. Retrieved from http://www.who.int/reproductivehealth/publications/maternal_perinatal_health/anc-positivepregnancy-experience/en/

World Health Organization (WHO). (2017). Maternal, newborn and child health in Nigeria. Retrieved from http://www.who.int/pmnch/activities/countries/nigeria/en/index3.html

The Journal of Social, Behavioral, and Health Sciences is an open-access, peer-reviewed, online interdisciplinary journal focusing on research findings that address contemporary national and international issues. Its objectives are to (a) encourage dialogue between scholars and practitioners in the social, behavioral, and health sciences that fosters the integration of research with practice; (b) promote innovative models of interdisciplinary collaboration among the social, behavioral, and health sciences that address complex social problems; and (c) inform the relationship between practice and research in the social, behavioral, and health sciences.

Walden University Publishing: http://www.publishing.waldenu.edu 